\title{
Fast fashion: pesquisa sobre a exploração da mão de obra em negócios de vestuário no Brasil
}

\author{
Fast fashion: research on \\ the exploitation of labor in \\ clothing business in Brazil
}

Vivian Andreatta Los ${ }^{[1]}$, Mariana Luísa Schaeffer Brilhante $^{[2]}$, Valdecir Babinski Júnior ${ }^{[3]}$, Gabrielly Eduarda Gretter $^{[4]}$, Gabriela Mueller Alegre Piontkiewicz ${ }^{[5]}$, Samira Gabrielly Ubinski[6]

\footnotetext{
Resumo: essa pesquisa teve como objetivo identificar os episódios, na história da moda, em que houve o surgimento do fast fashion e do emprego de mão de terceirizada composta por trabalho análogo à escravidão. A metodologia foi pautada em pesquisas bibliográficas e no aplicativo Moda Livre ${ }^{\circledR}$, do qual foram extraídas informações acerca de empresas auditadas. Constatou-se que: (I) em meados de 1990, a escravidão contemporânea começou a ser questionada dentro da indústria de confecção; (II) de 1994 até 2014, cresceram as denúncias de trabalho
}

[1] Mestra em Educação, FURB.

[2] Mestranda em Design de Vestuário e Moda, UDESC. marsbxx@gmail.com

[3] Mestre em Design de Vestuário e Moda, UDESC. vj.babinski@gmail.com

[4] Estudante do Curso Técnico Integrado em Modelagem

do Vestuário, IFSC. gabriellygretteroo8@gmail.com

[5] Estudante do Curso Técnico Integrado em Modelagem

do Vestuário, IFSC. gabii.muller.alegri@gmail.com

[6] Estudante do Curso Técnico Integrado em Modelagem

do Vestuário, IFSC.samiraubinski@gmail.com 
escravo ligadas ao fast fashion; (III) a partir de 2019, pela pressão do mercado consumidor e de novas legislações, varejistas mundiais passaram a adotar práticas de fair trade (comércio justo, em livre tradução); e, atualmente, (IV) percebe-se que, de 41 empresas autuadas no Moda Livre ${ }^{\circledR}, 25$ estão cadastradas na Associação Brasileira de Varejo Têxtil (ABVTEX) que, por sua vez, realiza auditorias para averiguar se as práticas de trabalho respeitam à dignidade humana.

Palavras-chaves: Exploração de mão de obra. Terceirização. Indústria de confecção brasileira.

Abstract: this research aimed to identify the episodes, in the history of fashion, in which there was the emergence of fast fashion and the employment of an outsourced workforce consisting of work analogous to slavery. The methodology was based on bibliographic research and on the Moda Livre ${ }^{\circ}$ application, from which information about audited companies was extracted. It was found that: (I) in the mid-1990s, contemporary slavery began to be questioned within the garment industry; (II) from 1994 to 2014, the denunciations of slave labor linked to fast fashion grew; (III) as of 2019, due to pressure from the consumer market and new legislation, world retailers began to adopt fair trade practices; and, currently, (IV) it is clear that, of $41 \mathrm{com}$ panies fined under Moda Livre ${ }^{\circledR}, 25$ are registered with the Brazilian Textile Retail Association (ABVTEX), which, in turn, conducts audits to verify whether work practices respect the human dignity.

Keywords: exploitation of labor. Outsourcing. Brazilian clothing industry.

\section{INTRODUÇÃo}

Esse artigo consiste em uma versão ampliada e revisada do resumo expandido Escravidão contemporânea em negócios de vestuário no Brasil (BR) de Los et al. (2021), que será publicado na quarta edição do Fórum Fashion Revolution, que ocorrerá em 2022.

Para Refosco, Oenning e Neves (2011), o termo Prêt-à-Porter surgiu em 1949, pelas mãos do estilista Pierre Cardin, como uma forma de produção organizada que buscava meIhorias na indústria de confecção sem abrir mão da qualidade das peças de vestuário da Alta Costura. Diferente do sindicato parisiense, o modelo proposto por Cardin favorecia a venda imediata. Porém, a partir da década de 1960, houve uma divisão do Prêt-à-Porter em três níveis fundamentais: (I) o clássico, vendido em grandes lojas; (II) o estilo, destinado para um público jovem; e (III) o luxo, comercializado no âmbito da alta sociedade (SALGADO, 2015). 
Dez anos se passaram e nasceu o termo fast fashion (moda rápida, em livre tradução para a língua portuguesa), em conjunto com o crescimento populacional e anseio por mais lucros, principalmente nas empresas europeias e norte-americanas (REFOSCO; OENNING; NEVES, 2011). Na década de 1970, com a proibição do comércio de petróleo para os Estados Unidos da América e alguns países europeus, as empresas em crise buscaram outros tipos de investimentos. De acordo com Fletcher e Grose (2011), o fast fashion foi criado com a intenção de incrementar as receitas de empresas do setor e melhorar a economia. A ideia inicial lançada foi a criação de coleções de peças de vestuário por semestre, depois por quadrimestre. Com o tempo, o lançamento das coleções precipitou-se e passou a seguir as estações do ano (GWILT, 2014).

No século XXI, a celeridade do processo de confecção de peças de vestuário imprimiu a necessidade de lançamentos trimestrais e, até mesmo, quinzenais. Avelar Júnior (2011, p. 161), ao estudar a pesquisa de Gabriela Ries (2002), traz os seguintes dados: "A Zara chega a produzir 12.000 modelos por ano. [...] O ciclo total de uma coleção é de 15 dias. Toda semana são trocadas 35\% das mercadorias de cada loja". Já a Riachuelo, conforme Avelar Júnior (2011, p. 164) também adotou "[...] a estratégia pautada em respostas rápidas (quick response), que implantou de fato o modelo fast fashion". Ou seja, segundo o autor, quinzenalmente, essas duas marcas apresentam novas Coleções Cápsulas para atraírem o cliente ao consumo. De acordo com o App Moda Livre ${ }^{\circledR}$ da Repórter Brasil, no ano de 2011, conforme relatam Pyl e Hashizume (2011, p. 1) "[...] fiscais do Ministério do Trabalho encontraram vítimas de trabalho análogo ao trabalho escravo advindas da Bolívia e do Perú, entre elas uma adolescente de 16 anos". Conforme Avelar Júnior (2011), essas coleções visam trazer, constantemente, peças de vestuário inéditas para o comércio, e podem ser compostas por 15 looks ou menos. Para o autor, esses looks incentivam o consumo, geralmente, a preços acessíveis. 
O relatório A new textiles economy: Redesigning fashion's future, por meio dos autores Banks et al. (2017), evidencia que grandes marcas - como: H\&M, Nike, Lenzing e C\&A - foram parceiras em divulgar os estudos sobre métodos para desacelerar o consumo excessivo e desordenado no mundo. Para reforçar esse pensamento, segundo o Aplicativo Moda Livre® (2018), medidas de transparência quanto às ações relativas ao cuidado com o trabalho escravo tornaram-se uma tendência internacional. Conforme consta no App Moda Livre ${ }^{\circledR}$ (2018) as empresas “Adidas, Calvin Klein, Levis, Nike e Puma divulgam o nome de seus fornecedores (terceirizados de costura) na internet".

A Associação Brasileira do Varejo Têxtil (ABVTEX, 2021) torna pública a lista de empresas de confecção aprovadas em seu programa de certificação, com auditorias frequentes em todas as empresas terceirizadas de costura. A divulgação dessa lista de empresas flagradas com trabalho contemporâneo análogo à escravidão contribui para a diminuição dos casos de escravidão em empresas de confecção terceirizadas. Mas, para que a poluição têxtil diminua e que os trabalhadores recebam melhores condições de trabalho, deve haver um redirecionamento das estratégias de produção e comercialização dos produtos, além de um investimento em peças de roupa mais duráveis e de maior qualidade.

Inspirado no conceito de slow food, que se originou na Itália nos anos 1990, o slow fashion adaptou alguns pontos para o âmbito da moda e surge cada vez mais forte. Esse conceito busca lutar pela venda e consumo de roupas mais duráveis, com valor agregado, métodos de fabricação menos poluentes e com condições de trabalho mais justas para seus colaboradores (LEGNAIOLI, 2021).

A produção em massa de roupas e acessórios, impulsionada pelo Fast Fashion, trouxe a necessidade de mão de obra barata e com alto índice de produção, com a geração de trabalho análogo à escravidão (BERLIM, 2016). A presente pesquisa tem, em sua justificativa, a necessidade de ex- 
plicitar a situação atual relativa ao fast fashion e ao trabaIho contemporâneo análogo à escravidão no Brasil, afinal, percebem-se significativas mudanças de comportamento nos negócios de vestuário.

Diante das questões que envolvem a indústria do vestuário, na presente pesquisa busca-se identificar os episódios, na história da moda, em que houve o surgimento do fast fashion e do emprego de mão de obra terceirizada composta por trabalho análogo à escravidão. Para isso, foi detalhado o desenvolvimento do fast fashion na história da moda e também a presença de contemporâneo trabalho análogo à escravidão em marcas de vestuário do Brasil.

Para alcançar o objetivo proposto, tornou-se necessário realizar uma pesquisa bibliográfica em sites, livros, jornais, revistas e aplicativos. A análise dos dados foi realizada por meio dos seguintes teóricos: para relacionar as diferenças entre fast fashion e Slow Fashion e o seu surgimento, utilizou-se Delpierre (1997), Klein (2002), Fletcher e Grose (2011), Berlim (2016), Coutinho e Kauling (2020), Legnaioli (2021), entre outros; para abordar o trabalho contemporâneo análogo à escravidão e o consumismo insustentável em negócios de vestuário, utilizou-se Klein (2002), Lee (2009), Fletcher e Grose (2011), Refosco, Oenning e Neves (2011), Pyl e Hashizume (2011), Gwilt (2014), Cândido (2018), Guimarães e Rodrigues (2018), Schulte (2019), Suzuki (2020), Chae e Hinestroza (2020), Instituto Fashion Revolution Brasil (2020), Coutinho e Kauling (2020), entre outros.

A presente pesquisa caracteriza-se como de natureza bibliográfica, com caráter descritivo. Para Gil (2008, p. 28) “As pesquisas deste tipo têm como objetivo primordial a descrição das características de determinada população ou fenômeno ou o estabelecimento de relações entre variáveis". Caracteriza-se como pesquisa bibliográfica pois, na fundamentação do artigo, realizou-se uma revisão bibliográfica assistemática em diferentes plataformas digitais de artigos e trabalhos científicos, bem como no Google acadêmico. A 
fundamentação teórica foi selecionada de acordo com a particularidade de pesquisas voltadas ao trabalho análogo à escravidão no Brasil, dentro da indústria de vestuário, com dados numéricos e constatações importantes para a área. Portanto, a pesquisa se enquadra como qualitativa e quantitativa, visto que traz dados sobre a quantidade de trabalhadores flagrados em situação de escravidão e a quantidade de autuações realizadas, além de analisar os dados qualitativamente com base na literatura. O próximo tópico aborda a história do fast fashion na moda.

\section{O FAST FASHION NA HISTÓRIA DA MODA}

A Revolução Industrial teve início na Inglaterra a partir da segunda metade do século XVIII (1760-1840). Segundo Sant'Anna (2009), essa Revolução está ligada à moda, pois foi a partir das máquinas de tecelagem e das conquistas técnicas relacionadas ao desenvolvimento de todo o processo produtivo que ela se estabeleceu e desenhou a vida urbana moderna. Quase um século depois, as indústrias de confecção potencializaram sua produção de maneira tal que surgiram alterações no modo de vestir das pessoas e na forma de vender peças de vestuário - como o prêt-à-porter (pronto para usar, em livre tradução para a língua portuguesa), por exemplo.

Para Avelar (2009), a expressão prêt-à-porter foi lançada entre 1948 e 1949, a partir da expressão ready-to-wear (pronto para vestir, em livre tradução), utilizada nos Estados Unidos da América para descrever a produção e a distribuição de peças de vestuário de forma rápida e eficiente após a Segunda Guerra Mundial. Ao estudar a obra de Delpierre (1997), o autor aponta uma divisão no prêt-à-porter e fragmenta-o em quatro níveis fundamentais, em especial, a partir de 1960: (I) clássico; (II) de estilo; (III) de luxo; e (IV) de difusão.

O prêt-à-porter clássico ofertava produtos de vestuário a serem vendidos nas magazines. Na época, o setor não se diferenciava das lojas de departamento do início do século. Por sua vez, o prêt-à-porter de estilo, surgido em 1964, obje- 
tivava a produção de peças de vestuário destinadas a mulheres jovens, com formas e cores mais ousadas do que outrora, comercializadas em boutiques - que passaram a oferecer coleções de vários criadores e estavam associadas ao estilo de vida de suas clientes. De outro modo, o prêt-à-porter de luxo voltava-se para a clientela da Alta Costura, que buscava alternativas para o dia a dia, preços menos exorbitantes, mas com alta qualidade no design, nos materiais e no feitio.

Já o prêt-à-porter de difusão representava os varejistas multinacionais, hoje exemplificados por meio de empresas como Zara (Inditex), Clemens \& August (C\&A), Hennes \& Mauritz (H\&M) e Riachuelo. Nesses negócios, o lançamento de novas coleções e a apresentação de novos produtos ocorre em espaços de tempo mais curtos que a maioria do setor vestuarista. Popularmente, esse modelo pode ser denominado de fast fashion (AVELAR, 2009; REFOSCO; OENNING; NEVES, 2011). Segundo os autores Refosco, Oenning e Neves (2011, p. 15):
A indústria fast fashion está ancorada em todo o resultado tangível produzido na Alta Costura e no Prêt-à-porter. No entanto, utiliza-se de diversas qualidades de matérias- primas, processos produtivos e atrai uma gama ainda maior de consumidores. A indústria da moda passou a objetivar números deixando em segundo plano a qualidade dos têxteis produzidos e o ciclo de vida do produto. Sendo assim, as falhas na idealização e concepção dos produtos podem acarretar em danos irreparáveis já que eliminam grande volume de lixo têxtil e resíduos no meio.

Klein (2002) e Holland et al. (2020) comentam que, a partir da década de 1990, as primeiras denúncias de trabalho análogo à escravidão em torno do fast fashion começaram a aparecer, em conjunto com as críticas às marcas e corporações do capitalismo que envolveram a confecção rápida a preços reduzidos. Esses debates também incluíram alertas sobre os impactos causados ao planeta e a dificuldade da rastreabilidade na cadeia têxtil e de confecção em escala global. Para Fletcher e Grose (2011, p. 126) "[...] fazer depressa significa que podemos fazer mais, e também gera mais impacto". Isso 
implica dizer que a confecção rápida pode gerar atividades impensadas, que provocam efeitos nocivos ao meio ambiente e à sociedade. Salcedo (2014) afirma que, por essa razão, o mau uso da força de trabalho de seus colaboradores tornou-se regular nas indústrias do modelo fast fashion.

Conforme aborda Salcedo (2014, p. 29), em Bangladesh, entre os anos de 2006 e 2013, “[...] mais de 1100 trabalhadores da indústria têxtil morreram devido às más condições de trabalho". A autora sustenta que o trabalho repetitivo, durante horas seguidas, com uma rapidez além de suas capacidades habituais, prejudica o corpo humano. O excesso de esforço físico gera doenças que podem levar à incapacidade laboral humana, além de prejudicar o processo de produção e criar despesas em longo prazo para os negócios de vestuário.

No modelo de produção fast fashion o conceito de fair trade geralmente torna-se esquecido devido à sede capitalista por lucros maiores e produção rápida e em grande escala. Segundo Pitombo, Giuliani e Pizzinatto (2017, p. 5), “[...] o entendimento do processo de fair trade possui uma relação intrínseca com a gestão das organizações sustentáveis". A prática do fair trade também é utilizada como estratégia de marketing nos últimos anos do século XXI, por empresas que querem se passar por empresas com foco sustentável, mas que, na verdade, não comprovam essas ações. Empresas que praticam o fair trade usam estratégias de negócios e atividades de produção que protejam e sustentem o meio ambiente e os recursos humanos e que defendam as leis trabalhistas. $\mathrm{Na}$ produção realizada pelo fast fashion tais práticas se tornam mais difíceis de serem seguidas.

No início do século XXI, o sistema do fast fashion foi discutido, repensado e redirecionado por fabricantes e consumidores. Como exemplo, cita-se o relatório A new textiles economy: redesigning fashion's future, lançado em novembro de 2017 pela Ellen MacArthur Foundation. Acerca do relatório, Banks et al. (2017) afirmam que o desenvolvimento de vestuário deve priorizar roupas com ciclo de vida prolongado e que 
possam ser recicladas, alugadas ou revendidas. Os autores apontam que as indústrias podem eliminar o uso de substâncias tóxicas e fibras plásticas nos tecidos ao substituí-las por insumos renováveis e, também, podem fazer da durabilidade um conceito atraente. O estudo ainda apresenta que o futuro sustentável depende da reciclagem mediada pela transformação do ciclo de produção das peças de vestuário, em especial, pelo redesenho das atividades de design, coleta e reprocessamento de produtos pós-consumo. A Figura 1 sumariza as recomendações de Banks et al. (2017).

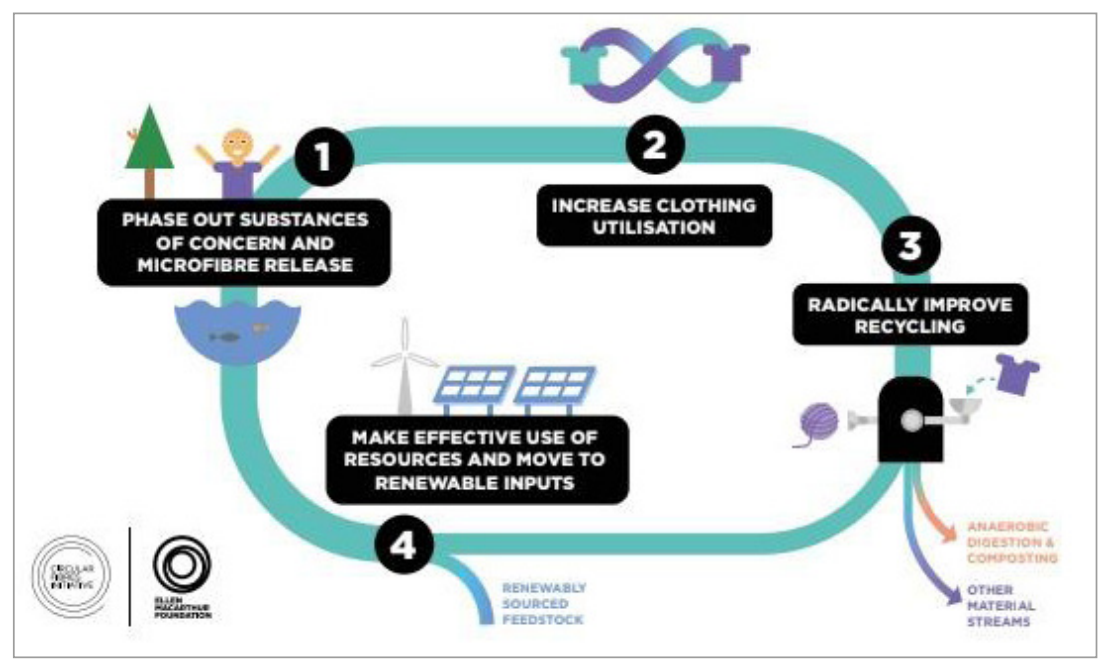

Figura 1: Ambiente para a nova economia têxtil Fonte: Banks et al. (2017, p. 23).

Banks et al. (2017, p. 50, tradução nossa) afirmam que a economia circular, apontada na Figura 1, introduz quatros “objetivos ambiciosos" para as próximas décadas:

1. Eliminar gradualmente as substâncias preocupantes e liberação de microfibra; 2. Transformar a maneira como as roupas são projetadas, vendidas e usadas para se libertar da natureza do descartável; 3. Melhorar radicalmente a reciclagem ao transformar o projeto de roupas, de coleção e de reprocessamento; 4. Fazer uso eficaz dos recursos e priorizar insumos renováveis. 
De acordo com Müller e Mesquita (2018), o consumismo exacerbado não torna os consumidores plenamente satisfeitos com suas aquisições, pelo contrário, as pessoas não precisam de novos produtos a todo momento para substituir produtos que ainda funcionam e atendem as suas necessidades. Segundo os autores, milhares de opções de escolhas tornam as pessoas ansiosas e confusas. Mas, o que traria equilíbrio a esse sistema de consumo exacerbado instaurado? Pode-se imaginar um sistema de consumo no qual produtores e consumidores fossem valorizados e por meio do qual o produto tivesse qualidade, porém com um preço que vai de encontro a esse nível de qualidade e fabricado com materiais ecologicamente corretos. Esse sistema de consumo existe e denomina-se slow fashion. A seguir, aborda-se o slow fashion, o trabalho contemporâneo análogo à escravidão no decorrer da história do vestuário e o consumo insustentável.

\section{SLOW FASHION, TRABALHO CONTEMPORÂNEO ANÁLOGO À ESCRAVIDÃO E O CONSUMO INSUSTENTÁVEL EM NEGÓCIOS DO VESTUÁRIO}

Antes de explorar a perspectiva do trabalho escravo, faz-se importante comentar sobre o sistema slow fashion. A produção de peças de roupas atemporais, na sua grande maioria, está atrelada ao feitio artesanal, com unidades avulsas confeccionadas com materiais de qualidade (SALCEDO, 2014). Diante disso, Schulte (2019) afirma que, nesse sistema, os processos de produção podem ser humanizados e podem estar alinhados com as leis trabalhistas. Refosco, Oenning e Neves (2011, p. 12) conceituam o termo como:

O Slow Fashion deriva do slow design e está ligado à desaceleração da moda, com peças perenes e esteticamente absorvidas em mais de uma estação. É antagônico aos produtos impessoais e homogêneos oferecidos pela fast fashion. Os produtos possuem maior qualidade, provenientes de uma moda clássica e durável. Outro fator importante é o respeito às fontes orgânicas e éticas, através da tentativa de preservar as tradições locais. 
Da mesma maneira que o exposto por Refosco, Oenning e Neves (2011) e Gwilt (2014) consideram que esse sistema tem como premissas: (I) redução do uso de produtos químicos nos tratamentos têxteis; (II) redução do uso de água e energia consumidas na fabricação e processos têxteis; (III) redução do desperdício de tecidos e recursos; e (IV) melhores condições de trabalho nas fábricas. A partir da premissa (IV), observa-se que a autora Gwilt (2014) estipula que, no sistema slow fashion, há o combate a quaisquer formas de trabalho análogo à escravidão.

A exploração excessiva de mão de obra e trabalho análogo à escravidão surgiram no período de colonização do Brasil, por volta do século XVI, quando indígenas que não aceitavam a catequização forçada eram usados como escravos pelos povos recém-desembarcados. Em busca de lucros frente à exploração de matérias-primas e extração de produtos locais, os colonizadores utilizavam os moradores nativos para os trabalhos manuais pesados em troca de alimento e moradia precária. Esse sistema cresceu e se consolidou mediante o capitalismo instaurado ao longo dos séculos seguintes (DORNELLES, 2018). Atualmente, o trabalho contemporâneo análogo à escravidão está presente em diversos setores da economia, sendo promovido por pequenos empresários e companhias de alto renome (HOLLAND et al., 2020).

Conforme a Associação Brasileira da Indústria Têxtil e de Confecção (ABIT, 2021) e a ABVTEX (2021), as costureiras podem ser consideradas a classe trabalhadora mais expressiva da moda e a que mais sofre por trabalho contemporâneo análogo à escravidão no Brasil, em relação à agroindústria e à construção civil. Isso porque o setor emprega oito milhões de brasileiros, dos quais 75\% são mulheres. Da parcela de trabaIhadores formais, modalidade que representa 1,6 milhões de empregos, 75\% são do segmento de confecção (ABIT, 2021). $O$ restante dos trabalhos encontra-se em situação de informalidade ou irregularidade, seja em subempregos ou como empreendedores autônomos. 
[...] no Brasil, [...] na indústria de vestuário e nas cadeias de fornecedores do fast fashion existe um número muito expressivo de mulheres trabalhando. [...] país que atualmente sofre ataques em suas estruturas de seguridade social, há um esforço dos dirigentes do país para fazerem florescer práticas do neoliberalismo. Devido aos desmontes do ministério do trabalho, as dimensões continentais do Brasil, a dificuldade de fiscalizar o trabalho e a flexibilização das leis, vemos o capitalismo em sua potência máxima da exploração não apenas da força de trabalho dos trabalhadores, mas também da força de vida (HOLLAND et al., 2020, p. 315-317).

Diante do excesso contingencial disponível e da massa de brasileiros desempregados, Coutinho e Kauling (2020), assim como Mello e César (2020), enfatizam que as empresas de vestuário tendem a fazer uso de trabalho análogo à escravidão, uma vez que exploram populações em condições de miserabilidade. Conforme os autores supracitados, em países em desenvolvimento há um incentivo para baixa fiscalização, o que torna raros os autos de infração dessas empresas. De modo semelhante, Suzuki (2020) observa que a grande maioria das pessoas escravizadas no país são migrantes oriundos da Bolívia, do Paraguai e do Peru. Por sua vez, Lee (2009, p. 100) constata que "[...] $76 \%$ das pessoas acham que o fim do trabalho infantil e da exploração da mão de obra são muito importantes para a produção ética, seguidos por itens como oferecer um preço justo aos produtores (60\%) e limitar os danos causados ao meio ambiente (50\%)".

Pelo apresentado por Lee (2009), percebe-se que os consumidores do início do século XXI já apresentavam prerrogativas de seleção mais apuradas em suas compras do que outrora. Mais de uma década depois do exposto por Lee (2009), em pleno período pandêmico ocasionado pela Sars-Cov-2 (Covid-19), nota-se que a sociedade perpassa construções do gosto que demandam pressões sobre o mercado. Essas pressões tornam a busca por barateamento na manufatura de novos produtos uma constante nas empresas do vestuário.

Melo (2020, n.p) destaca que "[...] quase 132 anos após a abolição da escravatura no Brasil, situações análogas ao 
trabalho escravo ainda são registradas". Segundo a autora, o Ministério Público do Trabalho (MPT) conta com 1,7 mil procedimentos de investigação para averiguar e libertar trabalhadores nessa situação. $\mathrm{O}$ trabalho análogo à escravidão urbano também fez 120 vítimas em 2019, sendo a maior parte na confecção de roupas, onde foram resgatadas 35 pessoas. 0 meio rural continua a ser o setor que mais têm trabalhos análogos à escravidão, tendo $87 \%$ dos casos. "São Paulo e Pará tiveram 25 ações fiscais, cada, sendo que em São Paulo foram resgatados 91 trabalhadores e no Pará, 66" (MELO, 2020, n.p).

Pyl e Hashizume (2011) sustentam que os trabalhadores das empresas de vestuário podem ser submetidos a mais de quatro horas de trabalho sem intervalo e a jornadas exaustivas que ultrapassam mais de 10 horas por dia. Conforme os autores, isso ocorre com mais facilidade em grandes centros urbanos, tais como capitais metropolitanas ou regiões de alta industrialização. Para combater essa prática, a Organização Não Governamental (ONG) Repórter Brasil criou o aplicativo Moda Livre ${ }^{\circledR}$ em 2013, para divulgar as empresas de vestuário que, tal como Zara, já foram flagradas em autuações policiais. Os autores ressaltam que essas autuações ocorrem, algumas vezes, por contratos irregulares com fornecedores terceirizados que se responsabilizam pelo processo de costura. Não raro, essas empresas terceirizadas submetem trabalhadores a condições desumanas em troca de comida e moradia.

A ONG Repórter Brasil possui duas áreas principais de atuação: (I) jornalismo; e (II) pesquisa. Por meio de ambas, a organização produz informações e análises que subsidiam lideranças sociais, políticas e econômicas, e também apresenta conteúdo que auxilia em metodologias educacionais para a difusão de informações sobre direitos humanos e intercâmbio de conhecimento (SUZUKI, 2020).

O aplicativo nacional Moda Livre ${ }^{\circledR}$, lançado em dezembro de 2013, foi desenvolvido pela ONG Repórter Brasil, referência nacional na defesa dos direitos humanos. Os membros da ONG avaliam grupos varejistas de moda em atividade no país, além de empresas em 
que a produção de roupa foi marcada por casos de trabalho escravo flagrado por fiscais do Ministério do

Trabalho e Emprego (MTE) (CÂNDIDO, 2018, p. 9).

Ao verificar as leis trabalhistas, o Art. 149 da Lei $\mathrm{n}^{\circ}$. 10.803/2003 aborda o assunto, descreve que o trabalho escravo consiste em:

Reduzir alguém à condição análoga à de escravo, quer submetendo a trabalhos forçados ou a jornada exaustiva, quer sujeitando-o a condições degradantes de trabalho, quer restringindo, por qualquer meio, sua locomoção em razão de dívida contraída com o empregador ou preposto (BRASIL, 2003).

Fletcher e Grose (2011, p. 121) salientam que “[...] há uma demanda crescente por um comércio justo e produtos orgânicos, além da rastreabilidade das matérias primas". Também concorda com essa visão Cândido (2018, p. 5), quando afirma: "O slow fashion vem se contrapor à moda rápida, sendo socialmente responsável por toda a etapa produtiva até o descarte dos produtos". Para esses autores, os seres humanos precisam lembrar que o planeta necessita de atitudes conscientes e adquirir produtos de marcas comprovadamente sustentáveis. Uma pesquisa recente sobre desenvolvimento sustentável traz afirmações importantes para o futuro na produção de vestuário:

[...] o desenvolvimento de roupas inteligentes requer a colaboração de diferentes disciplinas e setores industriais, a transparência de dados e informações de roupas inteligentes, materiais constituintes e processos de manufatura avançados devem ser introduzidos por meio de novos padrões de design (CHAE; HINESTROZA, 2020, p. 2).

Os autores Chae e Hinestroza (2020) ainda reforçam que a transparência dos dados relacionados ao modo como são fabricadas as roupas é primordial para que não ocorra a disseminação do trabalho contemporâneo análogo à escravidão. 
Nesse sentido, no Brasil, ações vêm sendo tomadas por meio da ONG Repórter Brasil (2018), pois, ao entrar no aplicativo Moda Livre (da ONG), tem-se acesso ao questionário que as empresas precisam responder para obterem boas avaliações quanto à sustentabilidade. Percebe-se aumento na frequência de respostas a essa ferramenta nos últimos três ou quatro anos. Os negócios de vestuário divulgam informações sobre seus terceirizados e sobre as auditorias internas para evitar a presença de trabalho análogo à escravidão na confecção de seus produtos (SUZUKI, 2020).

A transparência dos dados relacionados ao modo como são fabricadas as roupas torna-se primordial para que não ocorra a disseminação do trabalho análogo a escravidão, ou como vem sendo chamado ultimamente, escravidão contemporânea. A Figura 2 mostra dados sobre o crescimento de flagrantes realizados pelo MTE de trabalhadores em condições análogas ao trabalho escravo no Brasil (MELLO; CÉSAR, 2020).

Para combater o trabalho análogo à escravidão, o Ministério do Trabalho e Emprego (MTE) em conjunto com a Secretaria de Direitos Humanos da Presidência da República, que mantém cadastros de empregadores que utilizam mão de obra análoga à escravidão, divulgam a chamada Lista Suja do Trabalho Escravo. Esse cadastro existe desde 2004 e é responsável por divulgar os flagrantes de trabalho análogo à escravidão em diferentes áreas do trabalho. A divulgação de tais dados, bem como o nome das empresas e/ou negócios que proporcionam esse tipo de trabalho torna-se importante na medida em que contribuem para a diminuição de casos. Na Figura 2, apresentam-se as pesquisas de divulgação nesse sentido, realizadas pela Repórter Brasil (1995). 
Veja dados gerais sobre trabalho escravo, ano a ano, de 1995 a 2014:

Número de trabalhadores libertados por ano

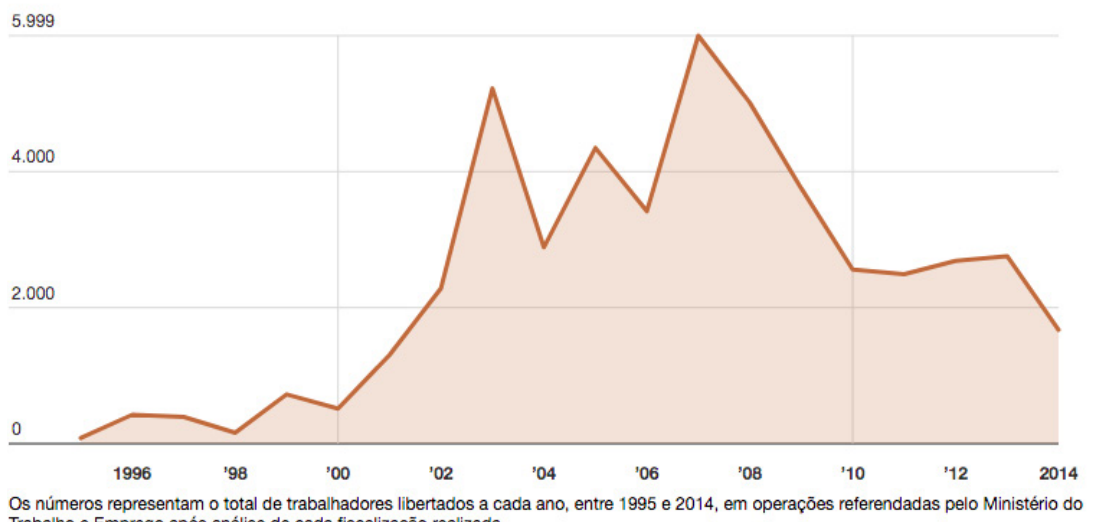

Trabalho e Emprego após análise de cada fiscalização realizada.

Em 2014 houve uma queda no número de flagrantes, porém, conforme dados disponíveis no aplicativo Moda Livre ${ }^{\circledR}$, no período de 1995 a 2018 já foram encontrados mais de 400 costureiros e costureiras em condições análogas à escravidão no Brasil.

Segundo Guimarães e Rodrigues (2018) e Mello e César (2020), atualmente a maioria dos negócios de vestuário trabalham com mão de obra terceirizada e até quarteirizada, ou seja, são tantas as empresas subcontratadas atuantes na maior parte das marcas de vestuário que se torna difícil o controle da presença do trabalho análogo à escravidão. $\mathrm{Na}$ obra de Guimarães e Rodrigues (2018, p. 2), observa-se que a terceirização tem como objetivo a transmissão a terceiros de tudo aquilo que as empresas "consideram estar fora de sua vocação" ou visa diminuir gastos com contratação de trabalhadores. Já a quarteirização é a coordenação, por parte da empresa quarteirizada, da gestão dos negócios realizados pelas empresas terceirizadas, "[...] sendo realizada na forma de subcontratação daquela que é a tomadora dos serviços". Ou seja, com tantas subcontratações o trabalho análogo à escravidão torna-se mais frequente.

Por meio das pesquisas no aplicativo Moda Livre ${ }^{\circledR}$ e das reportagens da ONG Repórter Brasil, a maioria dos casos de
Figura 2: Gráfico de flagrantes de trabalho análogo à escravidão no Brasil Fonte: Repórter Brasil (1995). 
situações análogas à escravidão ocorrem em pequenas confecções terceirizadas. As vítimas mais comuns são migrantes sul-americanos que trabalham em oficinas com condições degradantes (MELLO; CÉSAR, 2020). A ONG Repórter Brasil percebeu que a maioria dos migrantes com trabalhos análogos à escravidão, no Brasil, moravam na grande São Paulo (SP), segundo pesquisas de Suzuki (2019). Foi realizado um projeto de educação e conscientização em escolas, para estudantes e professores a respeito do assunto, em parceria com a Comissão Municipal de Erradicação do Trabalho Escravo do estado.

$\mathrm{Na}$ perspectiva do aplicativo Moda Livre ${ }^{\circledR}$, percebe-se o uso dos princípios supramencionados na apresentação de dados sobre migrantes em trabalhos análogos à escravidão. Suzuki (2019), em sua pesquisa, destaca que, entre 1995 e 2018, 561 trabalhadores foram resgatados dessa situação e que, entre os libertos, predominavam vítimas vindas da Bolívia, do Paraguai e do Peru. Importa destacar que, no decorrer desses 23 anos vislumbrados por Suzuki (2019), foi criada a Comissão Nacional para Erradicação do Trabalho Escravo (Conatrae).

Em 2008, a Conatrae aprovou o II Plano Nacional para a Erradicação do Trabalho Escravo (II PNETE). Trata-se de um compromisso público que apresenta 66 propostas de ações para eliminar o trabalho contemporâneo análogo à escravidão no Brasil (MONITORA 8.7, 2018). Para a ABIT (2021, n.p), $68,4 \%$ dessas ações já foram atingidas total ou parcialmente, sendo que "[...] 17 dos 33 indicadores (51,5\%) foram parcialmente cumpridos, 9 (27,3\%) foram cumpridos integralmente e $7(21,2 \%)$ não foram cumpridos". Ou seja, apesar dos avanços, 21,2\% das ações para o combate ao trabalho análogo à escravidão não puderam ser alcançadas e 31,6\% ainda não foram implementadas.

Também foi realizada uma verificação das informações presentes no aplicativo Moda Livre ${ }^{\circ}$ sobre flagrantes de trabalho análogo à escravidão no Brasil entre os anos de 2009 a 2021, e constatou-se que 557 pessoas foram libertas dessa 
condição pelo MTE. De 2018 a 2021 foram resgatadas 84 pessoas encontradas nessa situação nas confecções do vestuário. Entre todos esses casos, pelo menos cinco jovens de 13 a 16 anos estavam em situação análoga à escravidão e viviam dentro das empresas, conforme apresenta a ONG Repórter Brasil (2021). Confirmam o exposto Fletcher e Grose (2011, p. 49), que definem que, "no setor de confecção da indústria têxtil [...], que em geral emprega mulheres entre 16 e 25 anos de idade, na maioria imigrantes vindos de áreas rurais que desconhecem seus direitos, quase nunca tem coragem de levantar a voz e, portanto, são facilmente exploradas". Corroboram ao assunto Holland et al. (2020, p. 313), quando afirmam que "[...] a respeito da escolaridade 39\% das pessoas resgatadas entre 2003 e 2018 cursaram o ensino fundamental até o quinto ano e 31\% são analfabetos, portanto são trabalhadores com pouco ou nenhum acesso à educação básica" que atuam nas empresas de confecção brasileiras.

Por fim, dados de 2021 do aplicativo Moda Livre ${ }^{\circledR}$ mostram que dos 132 negócios de vestuário investigados, 40\% possuem autuações por flagrante de trabalho análogo à escravidão, conforme o Ministério do Trabalho e Emprego (MTE). Isso significa dizer que a escravidão contemporânea continua a existir, apesar dos esforços do Estado e do terceiro setor. A indústria de confecção permanece como lócus da exploração da força de trabalho sob condições ilegais. Schulte (2019) e Cançado (2020) afirmam que o Brasil, por meio de associações como a ABVTEX, busca conscientizar os fabricantes quanto ao assunto, por meio de Certificação de Responsabilidade Social e monitoramento da cadeia produtiva têxtil. Nesse sentido, buscou-se realizar pesquisas junto ao site da ABVTEX e verificar quais empresas que constam no aplicativo Moda Livre ${ }^{\circledR}$ estão associadas a ela. Esses dados se encontram a seguir, no Quadro 1. 
Quadro 1: A relação entre os associados da ABVTEX, as auditorias internas e os flagrantes de trabalho contemporâneo análogo à escravidão de 2010 a 2017

\begin{tabular}{|c|c|c|}
\hline $\begin{array}{l}\text { Negócios de Moda } \\
\text { associados à ABVTEX }\end{array}$ & $\begin{array}{l}\text { Autuadas por } \\
\text { Trabalho Escravo } \\
\text { Contemporâneo }\end{array}$ & $\begin{array}{l}\text { Atualmente, fazem auditorias para } \\
\text { averiguar trabalho análogo à escravidão? } \\
\text { Se sim, qual empresa faz? }\end{array}$ \\
\hline Aramis menswear & Não & Sim. \\
\hline Arezzo \& Co & Não & Sim. \\
\hline Animale (Grupo Soma) & 2017 & Sim, trimestralmente. COTECNA e ABVTEX. \\
\hline A.Brand (Grupo Soma) & 2017 & Sim, trimestralmente. COTECNA e ABVTEX. \\
\hline $\begin{array}{l}\text { Bo.Bô e Le Lis Blanc } \\
\text { (Grupo Restoque) }\end{array}$ & 2013 & $\begin{array}{l}\text { Sim, entre seis e } 12 \text { meses. ABVTEX, } \\
\text { SGS, Bureau Veritas, Intertek. }\end{array}$ \\
\hline $\begin{array}{l}\text { Brooksfield Donna } \\
\text { (Grupo Via Veneto) }\end{array}$ & 2016 & $\begin{array}{l}\text { Sim, entre três e seis meses. ABNT, Bureau } \\
\text { Veritas, SGS, DNV-GL e Intertel. }\end{array}$ \\
\hline $\mathrm{C} \& \mathrm{~A}$ & 2012 & Sim, uma vez por ano. ABVTEX. \\
\hline Calvin Klein & Não & Sim, uma vez por ano. ABVTEX. \\
\hline Carrefour & Não & Sim, uma vez por ano. ABVTEX. \\
\hline Centauro & Não & Sim, uma vez por ano. ABVTEX. \\
\hline Hering (Grupo Soma) & Não & Sim, trimestralmente. COTECNA e ABVTEX. \\
\hline Dafiti Group & Não & Sim, uma vez por ano. ABVTEX. \\
\hline GPA (supermercados) & Não & Sim, uma vez por ano. ABVTEX. \\
\hline Grupo Big & Não & Sim, uma vez por ano. ABVTEX. \\
\hline
\end{tabular}




\begin{tabular}{|c|c|c|}
\hline $\begin{array}{l}\text { Negócios de Moda } \\
\text { associados à ABVTEX }\end{array}$ & $\begin{array}{l}\text { Autuadas por } \\
\text { Trabalho Escravo } \\
\text { Contemporâneo }\end{array}$ & $\begin{array}{l}\text { Atualmente, fazem auditorias para } \\
\text { averiguar trabalho análogo à escravidão? } \\
\text { Se sim, qual empresa faz? }\end{array}$ \\
\hline Grupo Malwee & Não & Sim, uma vez por ano. ABVTEX. \\
\hline Inbrands & Năo & Sim, uma vez por ano. ABVTEX. \\
\hline Lojas Americanas & 2013 & Sim, entre 12 e 24 meses. ABVTEX. \\
\hline Loungerie & Năo & Sim, uma vez por ano. ABVTEX. \\
\hline Marisa & 2010 & Sim, duas vezes por ano. BSCI ABVTEX. \\
\hline Netshoes & Não & Sim, entre 12 e 24 meses, ABVTEX \\
\hline $\begin{array}{l}\text { Pernambucanas } \\
\text { (Argonaut) }\end{array}$ & $\begin{array}{l}2010 \\
2011\end{array}$ & $\begin{array}{l}\text { Sim, uma vez por ano. ABVTEX, } \\
\text { SGS, Bureau Veritas. }\end{array}$ \\
\hline Renner & 2014 & Sim, a cada 4 meses. ABVTEX e interna. \\
\hline Reserva & Năo & $\begin{array}{l}\text { Sim, uma vez por ano. ABVTEX, } \\
\text { SGS, Bureau Veritas. }\end{array}$ \\
\hline Zara (grupo Inditex) & 2011 & Sim, uma vez por ano. ABVTEX. \\
\hline Rihappy & Năo & Sim, uma vez por ano. ABVTEX. \\
\hline Riachuelo & Nao & $\begin{array}{l}\text { Sim, uma ou duas vezes por ano. SGS, } \\
\text { Bureau Veritas, Intertek e ABNT }\end{array}$ \\
\hline
\end{tabular}

Fonte: adaptado dos sites ABVTEX (2021), Repórter Brasil (2021) e Aplicativo Moda Livre ${ }^{\circledR}$ (2021).

Por meio do Quadro 1 percebe-se há um grande número de empresas que se associaram à ABVTEX (2021) atualmente e que, por sua vez, essa realiza auditorias para averiguar se 
nas práticas de trabalho estão presentes índices de trabalho escravo contemporâneo ou situações análogas à escravidão.

Ao se deparar com situações de trabalho análogo à escravidão no Brasil, o empregado pode procurar os serviços de Centros de Referência de Assistência Social (CRAS) e Secretarias estaduais e municipais de Assistência Social, que visam garantir seus direitos. Para que os índices de trabalho análogo à escravidão diminuam, uma série de fatores devem ser melhorados no setor vestuarista, entre eles pode-se citar: (I) a oferta de salários justos; (II) a fiscalização de seus terceirizados por meio de auditorias internas; (III) a transparências das informações quanto ao número de autuações pelo MTE; e (IV) ações pró-sustentabilidade.

Segundo o Índice de Transparência Moda Brasil, organizado pelo Fashion Revolution CIC e Instituto Fashion Revolution Brasil (2020, p. 4), em análise dos negócios de vestuário brasileiros constatou-se que "[...] mais da metade das marcas e varejistas analisadas são pouco - ou nada - transparentes em relação às questões sociais e ambientais". Sendo que "[...] 21 de 40 (53\%), pontuaram abaixo de 15\%" em níveis de transparência de seus dados. "No entanto, proporcionalmente há menos marcas que zeraram suas pontuações em relação a 2018 e 2019 , correspondendo a 33\% em 2020, contra 43\% em 2019 e 40\% em 2018". Ou seja, há um movimento lento, mas crescente, com relação ao nível de transparência das empresas de vestuário quanto às suas ações sustentáveis. Ainda assim, o volume de não participantes desse índice ainda é alto (INSTITUTO FASHION REVOLUTION, 2020).

Olhando para as futuras gerações, segundo a Organizações das Nações Unidas (ONU, 2021), os Objetivos de Desenvolvimento Sustentável trazem um apelo global a fim de acabar com a pobreza, proteger o meio ambiente e o clima além de garantir que as pessoas, em todos os lugares, possam desfrutar de paz e de prosperidade. Esses são os objetivos que contribuem para atingir a Agenda 2030 no Brasil, que tem como oitava meta o trabalho decente a todos e cres- 
cimento econômico. Sua décima meta é o consumo e a produção responsáveis. Sobre o exposto, Cândido (2018, p. 10) afirma que, "[...] mesmo que façam parte de áreas diferentes da cadeia de moda, empresários, designers e consumidores precisam agir de maneira que o produto de moda seja um bem de maior durabilidade, qualidade e que respeite todos os trabalhadores envolvidos no processo". Isso implica dizer que deve ser um esforço mútuo de todos os envolvidos, tanto na cadeia produtiva quanto na comercialização e compra dessas peças de vestuário.

Conforme Babinski et al. (2021, p. 108) desde a

Revolução do Consumo do século XVI até a [...] contemporaneidade, a expansão da dinâmica da Moda [...] transcende o vestuário [...] Nesse sentido, quando o valor simbólico pende para a sustentabilidade, a relação pessoa-objeto passa a abarcar lições sobre a economia verde e surgem consumidores dissidentes do outrora consagrado consumo civilizatório [...].

Ou seja, consumidores éticos e que optam por decidir comprar somente produtos de origem sustentável passam a predominar na contemporaneidade. A seguir, as considerações finais dessa pesquisa podem ser observadas.

\section{CONSIDERAÇÕES FINAIS}

A pesquisa obteve êxito no cumprimento do objetivo ao evidenciar que o trabalho contemporâneo análogo à escravidão ainda assombra o Brasil. Com base em consultas ao aplicativo Moda Livre ${ }^{\circ}$, observou-se que 45 casos de flagrantes por trabalho análogo à escravidão já foram realizados desde o ano de 2010, onde mais de 400 trabalhadores, entre homens e mulheres, já foram libertos dessa situação. Historicamente, tratam-se de casos de emprego de migrantes que foram traficados de outros países latino-americanos - para serem utilizados como mão de obra em empresas que abastecem os negócios do modelo fast fashion - ou, ainda, migrantes clandestinos. 
Distantes das estratégias de fair trade, essas empresas exploram a miserabilidade humana em troca do aumento na margem de lucro dos serviços prestados aos varejistas do setor de vestuário. Trabalhos análogos à escravidão, na indústria da moda, são majoritariamente compostos por muIheres com baixa escolaridade e pouca instrução profissional, que se veem impossibilitadas de buscar seu sustento de outra forma, haja vista que sua condição está atrelada ao pagamento de dívidas em troca de comida e moradia.

Estima-se que a presente pesquisa possa contribuir com a comunidade acadêmica na formação de futuros profissionais capazes de flagrar e denunciar situações de trabalho análogo à escravidão, bem como possa denotar, aos negócios do modelo fast fashion, que há consumidores vigilantes que zelam pela preservação da ética do ambiente de trabalho nessas indústrias.

A maioria das empresas que em 2018 e 2019 não divulgavam seus dados, passaram a se associar à ABVTEX, na busca pela melhoraria de seus procedimentos internos quanto à sustentabilidade. A ABVTEX é responsável por um programa do varejo de moda de boas práticas na cadeia de fornecimento, que visa um ambiente sustentável e com condições dignas de trabalho (ABVTEX, 2021).

Organizado pela ONG Fashion Revolution, o índice de transparência mostra que há um movimento lento e crescente em relação ao nível de transparência das empresas de vestuário sobre as suas ações sustentáveis. Entretanto, o volume de não participantes desse índice ainda é alto. 


\section{REFERÊNCIAS}

ABIT. Abit apoia combate ao trabalho escravo. ABIT, 2021.

Disponível em: https://www.abit.org.br/noticias/abit-apoiacombate-ao-trabalho-escravo. Acesso em: 28 maio 2021.

ABIT. Perfil do Setor: Dados gerais do setor referentes a 2019 (atualizados em dezembro de 2020). ABIT, 2020. Disponível em: https://www.abit.org.br/cont/ perfil-do-setor. Acesso em: 28 maio 2021.

ABVTEX. Nosso propósito. 2021. Disponível em: https://www.abvtex.org.br/. Acesso em: 5 jun. 2021.

AVELAR JÚNIOR, O. V. de. Estratégia de marcas próprias nas lojas de departamentos. Ciências Administrativas, Fortaleza (CE), vol. 17, núm. 1, abril pág. 146-179, 2011. Disponível em: https://www.redalyc.org/ pdf/4756/475647552005.pdf. Acesso em: 19 maio 2021.

AVELAR, S. Moda: globalização e novas tecnologias. São Paulo: Estação das Letras e Cores, 2009.

BABINSKI JÚNIOR, V. et al. Moda e Consumo Sustentável: um exemplo de Florianópolis (SC). Mix Sustentável, Florianópolis, v. 7, n. 1, p. 93-110, 21 dez. 2020. Disponível em: https://ojs.sites.ufsc.br/index.php/mixsustentavel/ article/view/4287. Acesso em: 8 mar. 2021.

BERLIM, L. Moda e sustentabilidade: Uma reflexão necessária. São Paulo: Estação das Letras e Cores, 2016.

BRASIL. LEI No. 10.803, DE 11 DE DEZEMBRO DE 2003. 2003. Disponível em: http://www.planalto.gov.br/ccivil_03/ leis/2003/l10.803.htm. Acesso em: 10 nov. 2021.

CANÇADO, F. B.; LEAL, C. R. F. A adoção de selos sociais como mecanismo de combate ao trabalho escravo contemporâneo na cadeia Têxtil e de Confecção do Vestuário. Forum Fashion Revolution, 2020. 
CANDIDO, B. M. Fashion Revolution Brasil: análise da interação entre consumidor e Marca. IFSC, 2018. Disponível em: https://repositorio.ifsc.edu. br/bitstream/handle/123456789/972/tcc.bruna_ maria_candido.pdf. Acesso em: 12 maio 2021.

CHAE, Y.; HINESTROZA, J. Building Circular Economy for Smart Textiles, Smart Clothing, and Future Wearables. Materials Circular Economy, SUÍÇA, 2: 2, 1-4, abril 2020. Disponível em: https://link.springer.com/article/10.1007/ s42824-020-00002-2. Acesso em: 15 maio 2021.

COUTINHO, M.; KAULING, G. B. Fast fashion e slow fashion: o paradoxo e a transição. Memorare, Tubarão, v. 7, n. 3, set./dez. 2020. Disponível em: http:// portaldeperiodicos.unisul.br/index.php/memorare grupep/article/view/10211. Acesso em: 4 fev. 2021.

DELPIERRE, M. Ville de Paris, Musée de la Mode et du Costume. Indispensables accessoires XVIeXXe SIÈCLE. Musée de la Mode et du Costume. Fragnolo — Itália: Editora UMBRA SAS: 1997.

DORNELLES, S. S. Trabalho compulsório e escravidão indígena no Brasil imperial: reflexões a partir da província paulista. Universidade Federal do Maranhão (UFMA), Departamento de História. São Luís, MA, Brasil. 2018. Disponível em: https://www.scielo.br/j/rbh/a/ rgy7QbXBkb5chc8xRvrMxsc/. Acesso em: 12 maio 2021.

FLETCHER, K.; GROSE, L. Moda e sustentabilidade: design para mudança. 1. Ed. São Paulo: Senac, 2011. GIL, A. C. Métodos de pesquisa social.

6. ed. São Paulo: Atlas, 2008.

GUIMARÃES, A. L. F.; RODRIGUES, K. R. de A. L. A quarteirização sob a ótica da reforma trabalhista.

Revista Jus Navigandi, ISSN 1518-4862, Teresina, ano 23, n. 5649, 19 dez. 2018. Disponível em: https://jus. com.br/artigos/70192. Acesso em: 9 ago. 2021. 
HOLLAND, H. M. et al. O trabalho análogo ao escravo na sociedade do hiperconsumo: uma análise das corporações transnacionais. In: CALGARO, C.

Constitucionalismo e Meio Ambiente, Tomo II: consumo

[recurso eletrônico]. Porto Alegre: Editora Fi, 2020.

INSTITUTO FASHION REVOLUTION. Índice de

Transparência da Moda no Brasil. 2020. Disponível

em: https://bit.ly/3e4hHek. Acesso em: 16 jun. 2021.

KLEIN, N. Sem Logo: A Tirania das Marcas em um

Planeta Vendido. Rio de Janeiro: Record, 2002.

LEE, M. Eco chic: o guia de moda ética para a consumidora consciente. São Paulo: Larousse do Brasil, 2009.

LEGNAIOLI, S. O que é slow fashion e por que adotar

essa moda? 2021. Disponível em: https://www.ecycle.

com.br/industria-da-moda/. Acesso em: 18 fev. 2021.

MELLO, L. M. de; CÉSAR, J. B. M. A exploração do

trabalho escravo contemporâneo na indústria brasileira

da moda. Cadernos Jurídicos da Faculdade de

Direito de Sorocaba, São Paulo, v. 1, p. 347-375, 2020.

Disponível em: https://www.fadi.br/revista/index.php/

cadernosjuridicos/article/view/63. Acesso em: 10 ago. 2021.

MELO, K. Brasil teve mais de mil pessoas resgatadas do trabalho escravo em 2020. Agência Brasil, 2020. Disponível em: https://agenciabrasil.ebc.com.br/direitos-humanos/ noticia/2020-01/brasil-teve-mais-de-mil-pessoas-resgatadasdo-trabalho-escravo-em. Acesso em: 23 jul. 2021.

MONITORA 8.7. II Plano Nacional para a

Erradicação do Trabalho Escravo. Ciclo 2018. Ações

e Metas, 2018. Disponível em: https://monitora87.

org/visualizaplano. Acesso em: 1 jul. 2021. 
MÜLLER, M.; MESQUITA, F. Admirável Moda Sustentável:

Vestindo um novo mundo. São Paulo: Artipol, 2018.

PITOMBO, T. D. de T., GIULIANI, A. C.; PIZZINATTO, N.

$K$. Fair Trade (Comércio Justo) como estratégia na

sustentabilidade empresarial. Unesp, Jaboticabal, 2017.

PYL, B.; HASHIZUME, M. Zara não comparece à Assembleia

Legislativa; CPI é defendida. Inpacto, 2011. Disponível em:

https://inpacto.org.br/zara-nao-comparece-a-assembleia-

legislativa-cpi-e-defendida/. Acesso em: 11 jun. 2021.

REFOSCO, E.; OENNING, J.; NEVES, M. Da Alta

Costura ao Prêt-à-porter, da Fast Fashion a Slow

Fashion: um grande desafio para a Moda. Moda

Palavra, UDESC. 2011. Disponível em: https://

www.periodicos.udesc.br/index.php/modapalavra/

article/view/7808/5376. Acesso em: 18 fev. 2021.

REPÓRTER BRASIL. Dados sobre trabalho escravo no Brasil. ONG Repórter Brasil, 2014. Disponível

em: https://reporterbrasil.org.br/dados/

trabalhoescravo/. Acesso em: 12 maio 2021.

REPÓRTER BRASIL. A moda de explorar o trabalhador.

ONG Repórter Brasil, 2016. Disponível em: https:// reporterbrasil.org.br/2016/08/a-moda-de-exploraro-trabalhador/. Acesso em: 17 jul. 2021.

REPÓRTER BRASIL. As marcas da moda flagradas com trabalho escravo. 2012. ONG Repórter Brasil, 2012. Disponível em: https://reporterbrasil.org.br/2012/07/ especial-flagrantes-de-trabalho-escravo-na-industriatextil-no-brasil/. Acesso em: 11 jun. 2021.

REPÓRTER BRASIL. Com Amissima, são 38 as marcas de moda envolvidas com trabalho escravo no Brasil. ONG Repórter Brasil, 2018. Disponível em: https:// reporterbrasil.org.br/2018/12/com-amissima-sao38-as-marcas-de-moda-envolvidas-com-trabalhoescravo-no-brasil. Acesso em 12 maio 2021. 
SALCEDO, E. Moda Ética Para Um Futuro Sustentável.

$1^{\text {a }}$ ed. São Paulo: Editora GG Brasil, 2014.

SALGADO, K. O Luxo e a Alta-costura: Uma análise

semiótica. Dissertação do Programa de Pós-Graduação

em Têxtil e Moda da Escola de Artes de Artes Ciências

e Humanidade da Universidade de São Paulo para

obtenção do título de Mestre em Ciências. 2015.150 p.

SANT'ANNA, P. Ciência e Cultura. MODA:

uma apaixonante história das formas. 2009.

Disponível em: http://cienciaecultura.bvs.br/scielo.

php?pid=S0009-67252009000100020. Acesso em: 9 fev. 2021.

SCHULTE, K. C. Compliance para moda sustentável. 2019.

São Paulo, E-book Fórum Fashion Revolution, 2019.

SUZUKI, N. O caderno: Escravo, nem pensar! no município de São Paulo. ONG Repórter Brasil, 2020. Disponível em: https://escravonempensar. org.br/wp-content/uploads/2020/06/enp_sp_20182019.pdf. Acesso em: 10 nov. 2021.

UNESCO. Aprender para se tornar parte do mundo. Educação para a sobrevivência futura, 2020. Disponível em: http://www.apcep.pt/docs/ APRENDER\%20PARA\%20SE\%20TORNAR\%20PARTE\%20

DO\%20MUNDO.pdf. Acesso em: 23 abr. 2021.

ONU. Sobre o nosso trabalho para alcançar os Objetivos de Desenvolvimento Sustentável no Brasil. 2021. Disponível em: https://brasil. un.org/pt-br/sdgs. Acesso em: 5 jun. 2021. 